American Journal of Pharmacology and Toxicology 4 (4): 127-129, 2009

ISSN 1557-4962

(C) 2009 Science Publications

\title{
Potent Antielastase and Antityrosinase Activities of Astilbe chinensis
}

\author{
${ }^{1}$ Seung-Hun Lee, ${ }^{1}$ Sandesh Sancheti, ${ }^{1}$ Shruti Sancheti and ${ }^{1,2}$ Sung-Yum Seo \\ ${ }^{1}$ Department of Biology, Kongju National University, Kongju 314-701, Korea \\ ${ }^{2}$ Korean Collection of Herbal Extracts, Inc., Kongju 314-701, Korea
}

\begin{abstract}
Problem statement: In the current scenario, photo-aging is a major problem causing skin wrinkling and hyperpigmentation. Therefore, elastase and tyrosinase inhibitors play an important role in the treatment of skin aging and thus, gaining a special attention in cosmetic industries. Approach: In the screening of Korean medicinal plants to search the potent elastase and tyrosinase inhibitors, the extract of the rhizomes of Astilbe chinensis (A. chinensis) exhibited the strongest potential. Further the crude $100 \%$ methanolic extract of A. chinensis along with its n-hexane, methylene chloride, ethyl acetate and aqueous fractions were investigated for elastase and tyrosinase enzyme inhibition activities. Results: The A. chinensis extracts showed remarkable elastase inhibitory activities (at a concentration of $20 \mu \mathrm{g} 155 \mu \mathrm{L}^{-1}$ reaction) ranging from $38-92 \%$ and tyrosinase inhibition activities (at a concentration of $20 \mu \mathrm{g} 150 \mu \mathrm{L}^{-1}$ reaction) ranging from 2-90\%. Among all the fractions, water fraction demonstrated the highest elastase and tyrosinase inhibitory activities (92 and 90\%, respectively). Conclusion: Based on the noteworthy antielastase and antityrosinase activities by the rhizome of A. chinensis, it might prove a strong candidate as an active ingredient in cosmaceutical formulations and further in vitro and in vivo investigations is needed.
\end{abstract}

Key words: Astilbe chinensis, elastase inhibition, tyrosinase inhibition

\section{INRODUCTION}

The skin is an important barrier that protects the body from damage due to direct contact with the outside environment. Among harmful environmental factors that damage the skin, UV irradiation is the most common and harmful. UV irradiation reduces skin elasticity and the linearity of dermal elastic fibers inducing wrinkle formation ${ }^{[1,2]}$. Moreover, UV irradiation sets in action an integrated mechanism for the formation and delivery of melanin within melanosomes from melanocytes to keratinocytes ${ }^{[3]}$.

Elastase is the only enzyme that is capable of degrading elastin, an insoluble elastic fibrous protein in animal connective tissues. It hydrolyses practically all proteins, including the supporting and structural proteins of the connective tissue, such as collagen and elastin. In UV-irradiated skin, mild inflammation occurs repeatedly in the dermis and it is assumed that connective tissue proteins may be attacked by elastase released from neutrophils, resulting in damage to elastin and finally causing sagging ${ }^{[4]}$.

Tyrosinase is one of the key enzymes in the melanin biosynthetic pathway: Tyrosinase catalyzes the oxidation of L-tyrosine to 3,4-Dihydroxyphenyl-LAlanine (L-DOPA), followed by the oxidation of L-
DOPA to dopaquinone. Subsequent oxidative polymerizations of several dopaquinone derivatives yield melanin ${ }^{[5-7]}$. Thus, use of tyrosinase inhibitors is becoming increasingly important in the cosmetic industry due to their skin-whitening effects, treatments for hyperpigmentation and solar lentigines by UVirradiation.

A. chinensis is a perennial herb that grows in China, Russia, Japan and Korea. The rhizomes of A. chinensis have been traditionally used to treat arthralgia, chronic bronchitis, headache and stomachalgia. Recent studies on the extract of A. chinensis rhizomes reported potential antiinflammatory ${ }^{[8]}$ and antitumor activities ${ }^{[0,10]}$ of this plant. In this research, we examined the inhibitory effects of A. chinensis rhizomes on elastase and tyrosinase enzymes to study the efficacy of it as a cosmaceutical agent.

\section{MATERIALS AND METHODS}

Plant material: The rhizomes of A. chinensis were obtained from "Korean Collection of Herbal Extracts", a Biotech company in Korea. A collection of voucher specimen is available with the company (Korean Collection of Herbal Extracts, 2000).

Corresponding Author: Sung-Yum Seo, Department of Biology, Kongju National University, Kongju, Korea Tel: 82-41-850-8503 Fax: 82-41-854-8503 
Extraction: The rhizomes of A. chinensis $(2 \mathrm{~kg}$, dry weight) were chopped into small pieces and kept for extensive decoction in $100 \%$ methanol for 3 days at room temperature. The extract was then concentrated using rotary vacuum evaporator at $20-30^{\circ} \mathrm{C}$ to obtain the dried crude extract $(150 \mathrm{~g})$.

Fractionation: The crude methanolic extract $(150 \mathrm{~g})$ was suspended in distilled water $(1 \mathrm{~L})$ and partitioned with $\mathrm{n}$-hexane, methylene chloride, ethyl acetate and nbutanol to yield the $\mathrm{n}$-hexane (15 g), methylene chloride (6 g), ethyl acetate $(52 \mathrm{~g})$ and aqueous $(70 \mathrm{~g}$ ) fractions, respectively. The enzyme inhibition activity assays were performed at concentration of $2 \mathrm{mg} \mathrm{mL}^{-1}$ for the crude extract and various fractions.

Reagents: All necessary chemicals and enzymes were purchased from Sigma-Aldrich (St. Louis, MO, USA). Other commercially available reagents and solvents were used as received.

Elastase assay: The elastase activity was evaluated according to the method previously reported by Kraunsoe et al..$^{[11,12]}$ with minor modifications. In order to evaluate the inhibition of elastase activity, the amount of released p-nitroaniline, which was hydrolyzed from the substrate, N-succinyl-Ala-AlaAla-p-nitroanilide, by elastase, was assayed by measuring absorbance at $410 \mathrm{~nm}$. In brief, $1.015 \mathrm{mM}$ solution of N-succinyl-Ala-Ala-Ala-p-nitroanilide was prepared in a $0.1 \mathrm{M}$ Tris-Cl buffer $(\mathrm{pH} 8.0)$ and this solution $(130 \mu \mathrm{L})$ was added to the test sample $(10 \mu \mathrm{L})$ in a 96 well microplate. The microplate was pre-incubated for $5 \mathrm{~min}$ at $25^{\circ} \mathrm{C}$ before an elastase $\left(0.5\right.$ Unit $\left.\mathrm{mL}^{-1}\right)$ stock solution $(15 \mu \mathrm{L})$ was added. After enzyme addition, the microplate was kept at $25^{\circ} \mathrm{C}$ for $30 \mathrm{~min}$ and the absorbance was measured at $410 \mathrm{~nm}$ using microplate reader. All experiments were carried out in triplicates.

Tyrosinase assay: The spectrophotometric assay was performed as described previously by Masamoto et al. ${ }^{[13]}$ with minor modifications. Ten $\mu \mathrm{L}$ of sample was added to 96 well micro plate. To these, $80 \mu \mathrm{L}$ of $67 \mathrm{mM}$ phosphate buffer (pH 6.8) and $30 \mu \mathrm{L}$ of $5 \mathrm{mM}$ L-DOPA was added. After incubating for $10 \mathrm{~min}$ at $37^{\circ} \mathrm{C}, 30 \mu \mathrm{L}$ of mushroom tyrosinase (200 units $\mathrm{mL}^{-1}$ ) was added. The reaction was monitored after $20 \mathrm{~min}$ for the formation of dopachrome by measuring optical density at $492 \mathrm{~nm}$ using micro plate reader. All experiments were carried out in triplicates.

\section{RESULTS}

The crude extract of A. chinensis and its various fractions were evaluated at $20 \quad \mu \mathrm{g} \quad 155 \quad \mu \mathrm{L}^{-1}$ concentrations for elastase enzyme inhibition studies.

All the A. chinensis extracts showed remarkable elastase inhibitory activities ranging from $38-92 \%$ and are shown (Fig. 1): Water (92\%) > crude extract (83\%) $>$ n-hexane $(78 \%)>$ methylene chloride $(58 \%)>$ ethyl acetate $(38 \%)$.

Tyrosinase inhibition results (at a concentration $20 \mu \mathrm{g} 150 \mu \mathrm{L}$ reaction $^{-1}$ ) are: Water $(90 \%)>$ crude extract $(78 \%)>$ ethyl acetate $(54 \%)>$ n-hexane $(5 \%)>$ methylene chloride (2\%). The water fraction showed the outstanding activity of tyrosinase inhibition (Fig. 2).

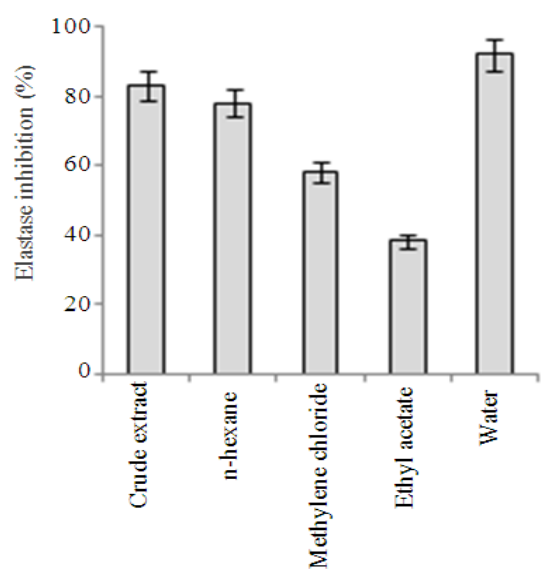

Fig. 1: Elastase inhibition by crude extract of A. chinensis and its fractions at $20 \mu \mathrm{g} 155 \mu \mathrm{L}^{-1}$ concentration

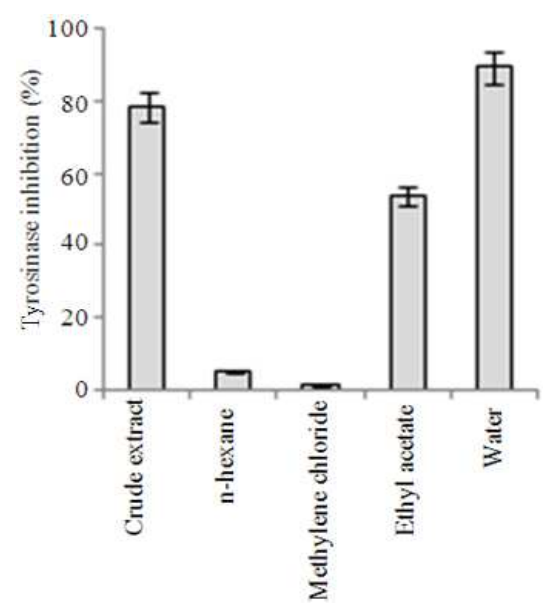

Fig. 2: Tyrosinase inhibition by crude extract of A. chinensis and its fractions at $20 \mu \mathrm{g} 150 \mu \mathrm{L}^{-1}$ concentration 


\section{DISCUSSION}

In the present study, some of the partitioned fractions of Astilbe chinensis extract showed remarkable elastase inhibition and tyrosinase inhibition activities, especially, water fraction showed the strongest inhibition against both the enzymes (Fig. 1 and 2).

Elastase plays a critical role in inflammatory processes $^{[14]}$. Also, it was reported that the A. chinensis extract has an inhibitory effect on UVB induced inflammation in human keratinocytes ${ }^{[15]}$. Thus, elastase inhibitors from A. chinensis are the important tools for studying the mechanisms of action of elastase and prospective ingredients for cosmetic and pharmacology industries. Furthermore, since the extract of A. chinensis showed the outstanding tyrosinase inhibition activities, the findings presented here suggest that extract of $A$. chinensis may have a role as a useful ingredient in cosmetics for wrinkle-care, skin-whitening and as phytopharmaceutical.

\section{CONCLUSION}

The results of the in vitro enzyme inhibition studies emphasize the potent effect of the A. chinensis rhizomes extract on elastase and tyrosinase inhibitions. Based on this, further pre-clinical and clinical studies can be pursued.

\section{REFERENCES}

1. Imokawa, G., 2008. Recent advances in characterizing biological mechanisms underlying UV-induced wrinkles: A pivotal role of fibrobrastderived elastase. Arch. Dermatol. Res., 300: 7-20. DOI: 10.1007/s00403-007-0798-x

2. Watanabe, H., T. Shimizu, J. Nishihira, R. Abe and T. Nakayama, 2004. Ultraviolet A-induced production of matrix metalloproteinase-1 is mediated by macrophage Migration Inhibitory Factor (MIF) in human dermal fibroblasts. J. Biol. Chem., 279: 1676-1683. DOI: 10.1074/jbc.M303650200

3. Costin, G.E. and V.J. Hearing, 2007. Human skin pigmentation: Melanocytes modulate skin color in response to stress. FEASB J., 21: 976-994. DOI: 10.1096/fj.06-6649rev

4. Lee, K.K., J.H. Kim, J.J. Cho and J.D. Choi, 1999. Inhibitory effects of 150 plant extracts on elastase activity and their anti-inflammatory effects. Int. J. Cosmet. Sci., 21: 71-149. DOI: 10.1046/j.14672494.1999.181638.x

5. Raper, H.S., 1928. The anaerobic oxidase. Physiol. Rev., 8: 245-282. http://physrev.physiology.org/cgi/content/citation/8 $12 / 245$
6. Kobayashi, T., W.D. Vieira, B. Potterf, C. Sakai, G. Imokawa and V.J. Hearing, 1995. Modulation of melanogenic protein expression during the switch from eu-to phenomelanogenesis. J. Cell Sci., 108: 2301-2309.

http://jcs.biologists.org/cgi/reprint/108/6/2301

7. Olivares, C., C. Jimenez-Cervantes, J.A. Lozano, F. Solano and J.C. Garcia-Borron, 2001. The 5,6dihydroxyindole-2-carboxylic acid (DHICA) oxidase activity of human tyrosinase. Biochem. J., 354: 131-139. http://www.pubmedcentral.nih.gov/picrender.fcgi?a rtid $=1221637 \&$ blobtype $=$ pdf

8. Moon, T.C., C.X. Lin, J.S. Lee, D.S. Kim and K. Bae et al., 2005. Antiinflammatory activity of astilbic acid from Astilbe chinensis. Biol. Pharm. Bull., $\quad 28$ : 24-26. http://www.ncbi.nlm.nih.gov/pubmed/15635157

9. Sun, H.X. and X.Y. Peng, 2008. Protective effect of triterpenoid fractions from the rhizomes of A.stilbe chinensis on cyclophosphamide-induced toxicity in tumor-bearing mice. J. Ethnopharmacol., 119: 312-317. DOI: 10.1016/j.jep.2008.07.017

10. Tu, J., H.X. Sun and Y.P. Ye, 2008. Immunomodulatory and antitumor activity of triterpenoid fractions from the rhizomes of Astilbe chinensis. J. Ethnopharmacol., 119: 266-271. DOI: $10.1016 /$ j.jep.2008.07.007

11. Kraunsoe, J.A., T.D. Claridge and G. Lowe, 1996. Inhibition of human leukocyte and porcine pancreatic elastase by homologues of bovine pancreatic trypsin inhibitor. Biochemistry, 35: 9090-9096. http://www.ncbi.nlm.nih.gov/pubmed/8703913

12. Kim, Y.H., C.B. Chung, J.G. Kim, K.I. Ko and S.H. Park, 2008. Anti-wrinkle activity of ziyuglycoside I isolated from a Sanguisorba officinalis root extract and its application as a cosmeceutical ingredient. Biosci. Biotechnol. Biochem., 72: 303-311. DOI: 10.1271/bbb.70268

13. Masamoto, Y., S. Linda and M. Kubo, 1980. Inhibitory effect of the Chinese crude drugs on tyrosinase. Planta Med., 40: 361-365. http://www.ncbi.nlm.nih.gov/pubmed/6784133

14. Wiedow, O., J.M. Schroder, H. Gregory, J.A. Young and E. Christophers, 1990. Elafin: An elastasespecific inhibitor of human skin. Purification, characterization and complete amino acid sequence. J. Biol. Chem., 265: 14791-14795. http://www.jbc.org/cgi/reprint/265/25/14791?view $=$ long \& pmid $=2394696$

15. Na, M., B.S. Min, R.B. An, W. Jin and Y.H. Kim, 2004. Effect of the Rhizomes of Astilbe chinensis on UVB-induced inflammatory response. Phytother. Res., $\quad 18$ : 1000-1004. http://www.ncbi.nlm.nih.gov/pubmed/15742355 